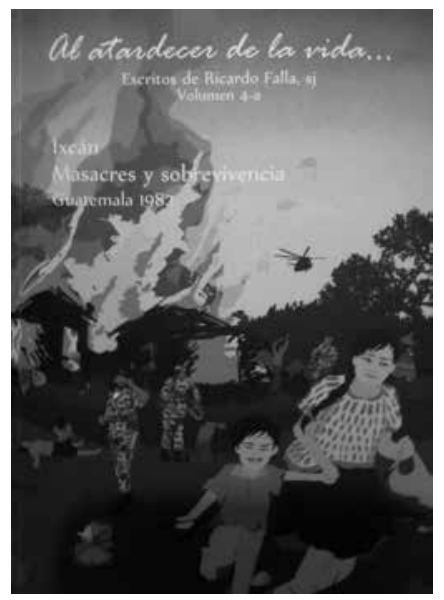

- Al atardecer de la vida...,

vol. 4: Ixcán. Masacres y sobrevivencia.

Guatemala 1982, tt. A y B

RICARDO FALLA, 2016

Asociación para el Avance de las Ciencias Sociales

en Guatemala/Universidad Rafael Landívar/

Universidad San Carlos de Guatemala, Guatemala

\title{
Resistir, un hacer para vivir
}

\author{
VIOLETA YURIKKO MEDINA TRINIDAD
}

Resistance, a Path for Living

VIOLETA YURIKKo MEDINA TRINIDAD

Escuela Nacional de Antropología e Historia,

Ciudad de México, México

hola465@hotmail.com

Desacatos 62,

enero-abril 2020, pp. 190-195
$1 \quad$ Hasta abril de 2019, se han publicado seis volúmenes de la serie. Tres de ellos se pueden descargar en: <http://avancso.org.gt/ricardo-falla-sj/coleccion-al-atarde cer-de-la-vida/>.

2 Avancso se fundó en 1986, después de un periodo de violencia y gobiernos militares, con la intención de generar conocimiento útil para los sectores más desfavorecidos, con un enfoque en la relación Estado-sociedad. Produjo las primeras investigaciones sobre desplazados y el conflicto armado en Guatemala (Avancso, s. f.).

3 El juicio fue anulado el mismo año, se argumentaron inconsistencias jurídicas y se ordenó que se realizara de nuevo. El juicio quedó inconcluso porque Ríos Montt murió el 1 de abril de 2018. 
por el asesinato de 1771 mayas ixiles, entre 1982 y $1983 .{ }^{4}$

En este contexto, Falla expone a modo de autoexamen y juicio público su testimonio, su biografía vinculada a una realidad diversa y cambiante (Avancso, 2014). Si bien la colección es heterogénea en cuanto a temas, detrás de cada volumen hay una preocupación genuina por la comprensión de lo Otro y su hacer cotidiano. ${ }^{5}$ Se expone su labor como sacerdote y su profundo interés antropológico por el ser y el quehacer humanos. Las publicaciones van desde lo más reciente, de 2012, hasta lo más antiguo, en un juego significativo con las portadas, en las que el paisaje comienza con un atardecer que va aclarando, mientras uno de los personajes — quizá el mismo Falla - porta un barrilete — papalote, cometa- que también se mueve con el transcurrir del tiempo.

El volumen 4, con dos tomos, ofrece una manera ejemplar de hacer trabajo de campo, en la que se mira a los sujetos de estudio como interlocutores conscientes y políticamente significativos (Rappaport y Rodríguez, 2007). Ricardo Falla llega en 1983 a la selva del Ixcán para "acompañar” a los sobrevivientes de algunas de las masacres más crueles cometidas durante el conflicto armado. Recién se empezaba a conocer lo que pasaba en la región y él se dio a la tarea de investigar qué había ocurrido. Comenzó a buscar a los sobrevivientes y entablar un diálogo profundo con ellos, que se mantendría cercano $^{6}$ a lo largo de casi 10 años. ${ }^{7}$ Durante ese tiempo, él vive y padece junto a los que se mantienen en resistencia, aprende lo que es vivir en la montaña, siempre en la escasez, a la sombra de los árboles y huyendo del Ejército, conoce también de organización y lucha. Tal vez por eso, cuando el Ejército descubre su "buzón", en 1992, le cuesta tanto abandonar a esa gente. ${ }^{8}$

Para todos los interesados en hacer trabajo de campo en zonas de violencia y conflicto, el texto ofrece una manera de vincularse al que padece una situación de sufrimiento y pérdida, una guía para comprender las circunstancias adversas y una gran fuerza para hacer que su voz valga.

En 700 páginas, Ricardo Falla cuenta una historia de terror pero también de amor a la tierra y la familia, la historia de quien vence a la muerte, "es contar como una buena noticia, 'yo estoy vivo"” (Falla, 2017). Este libro ha "salido a la luz" en fechas recientes, ${ }^{9}$ pero fue escrito hace más de

4 Ríos Montt accedió al poder después de un golpe de Estado. Su régimen fue uno de los más violentos del conflicto armado en Guatemala (1960-1996), cuyo saldo se calcula en 200000 asesinatos y 45000 desaparecidos, un millón de desplazados internos, 500000 refugiados, más de 600 masacres, 50000 viudas, 250000 niños huérfanos y 440 comunidades arrasadas. Se estima que $93 \%$ de las violaciones documentadas, 92\% de las ejecuciones arbitrarias y $91 \%$ de las desapariciones forzadas estuvieron en manos del Estado y grupos afines a él (CEH, 1999). En estas cifras no se toman en cuenta los muertos por desnutrición y enfermedad a consecuencia del desplazamiento y la persecución.

5 Como en otros textos que no pertenecen a la colección. En Alicia: explorando la identidad de una joven maya (Falla, 2005), desvela las penas y sentimientos de una joven del Ixcán, en el marco de un análisis complejo sobre los procesos de construcción de identidad.

6 Falla sigue en comunicación con la gente del Ixcán. Parte muy importante de esta colección es presentar los libros que ha hecho con la gente que integró las Comunidades de Población en Resistencia (CPR).

7 La experiencia de acompañamiento pastoral se expone en el volumen 5 de la serie. Sólo se ha publicado la primera parte (Falla, 2018).

$8 \quad$ Una especie de cueva que la gente hacía en la selva para guardar documentos o intercambiar correspondencia. En el caso de Falla, estaban los listados de bautizo -al parecer sólo las copias, no los originales- y sus documentos de identidad, que le servían para cruzar la frontera con México. Así, el Ejército supo que él estaba ahí, por lo que tuvo que abandonar con urgencia el Ixcán y después Guatemala.

9 "Ha salido a la luz o al claro" fue la expresión que se usó cuando las CPR tomaron la decisión de recortar las copas de los árboles, ver la luz del sol y dejar la clandestinidad. Este libro hace lo propio, deja de ser clandestino con su publicación. 
30 años. Conserva una gran fuerza, casi tanta como los testimonios que lo componen, recogidos en la efervescencia del momento, entre septiembre de 1983 y febrero de 1984, en medio de la lucha por sobrevivir, lo que los provee de un aliento de vida y "aguante".

El libro abarca un periodo corto en relación con la historia de Guatemala, pero es crucial para comprender los conflictos y dificultades que el país atraviesa en la actualidad. Narra de manera minuciosa, como quien va siguiendo las huellas del guía del camino, las masacres, persecuciones y desapariciones cometidas por el Ejército guatemalteco entre febrero y octubre de 1982, en la región del Ixcán.

\section{Ixcán, el paraíso prometido}

La región del Ixcán está en la parte noroccidental de los departamentos del Quiché y Huehuetenango, limita al norte con México y se ubica entre los ríos Ixcán —Lacantún en México-y Chixoy. Falla dedica un tomo completo a analizar la historia de su conformación en Ixcán. El campesino indígena se levanta. Guatemala 1966-1982 (2015).

El Ixcán se pobló de manera masiva apenas a principios de la década de 1960 y se divide en dos grandes secciones, la zona Reina e Ixcán Grande. La segunda fue parte de un proyecto de la Iglesia católica, en el marco de la teología de la liberación, que buscaba ofrecer una alternativa a los campesinos que sufrían explotación en las fincas de la costa sur. El llamado tuvo eco y muy buena recepción, para finales del decenio había 181 parcelistas, sobre todo indígenas provenientes de Huehuetenango. A principios de la década de 1970, la Cooperativa de Ixcán Grande ya estaba conformada. Esto requirió gran trabajo y organización, la población se enfrentó a la selva e hizo crecer el proyecto. Sin embargo, la selva no sería el único obstáculo, ni el más difícil, al que se enfrentaría.
Ixcán es un territorio rico, objeto de muchas ambiciones, en el que convergen otros proyectos, como el de la Franja Transversal del Norte (FTN), ${ }^{10}$ razón por la cual también había presencia constante del Ejército. A comienzos de la década de 1970, los grupos guerrilleros hicieron su aparición en la zona y poco a poco ganaron cierta simpatía entre la gente. Todo esto hacía - y hace - de Ixcán un lugar peculiar, ocupado por gente decidida a cambiar con trabajo sus condiciones de vida, pero con una larga historia de abuso e injusticia, con contradicciones propias de una colonización interna muy arraigada, con tierra abundante y pródiga, pero en disputa constante.

En este contexto, Falla presenta un fragmento de la gran ofensiva del Ejército, emprendida durante el gobierno del general Romeo Lucas García en Chimaltenango, al sur del Quiché, a mediados de noviembre de 1981. La intención era cortar de tajo la relación entre la población civil y la guerrilla, con masacres masivas e indiscriminadas, política de Tierra Arrasada y genocidio.

Falla muestra el orden riguroso que siguió el Ejército desde el 13 de febrero de 1982, el ataque a varios poblados durante los fines de semana, de Oriente, río Chixoy, a Occidente del Ixcán. La

10 El proyecto de la FTN - una banda de tierra que se extiende de Oeste a Este a lo largo del Sur del Petén, incluye partes de los departamentos de Izabal, Alta Verapaz, El Quiché y Huehuetenango- era promovido por el Instituto Nacional de Transformación Agraria y posteriormente por la Agencia Internacional de Desarrollo de Estados Unidos. Buscaba colonizar la parte norte del Quiché, en tierras que aún eran propiedad del Estado. Se buscaba mano de obra barata para las fincas y acceso al área para facilitar la extracción de petróleo y otros recursos naturales (Garst, 1993: 22; Brett, 2007: 28). El proyecto, y con él la construcción de la autopista, fue retomado en 2008 , en medio de disputas, conflictos y resistencias por parte de las comunidades afectadas. 
intención, nos dice, era erradicar a la población enemiga, quitarles desde los utensilios básicos cotidianos hasta la vida.

En el relato de las masacres, Falla presenta uno a uno a los actores — mujeres, niños, ancianos, parcelistas, comisionados, guerrilleros y soldados-, dibujados y comprendidos en su complejidad. Llama mi atención de manera particular el énfasis que pone en los niños, quienes suelen estar ausentes en este tipo de análisis. Los niños son colocados en una extensa gama de acciones y escenarios, como agentes activos en la producción de alimento y vigilancia en las postas, hasta su exterminio como representantes de la semilla de la resistencia. Falla hace hincapié en su manera de reaccionar durante las masacres, dice que actúan más rápido y con intuición frente al peligro latente del Ejército, tal vez por estar menos ideologizados. Algunos adultos, al contrario, están más atados a cuestiones materiales e ideológicas.

Debido, entre otras cosas, a la historia de la región y su diversidad étnica y religiosa, se gestaron múltiples posturas ideológicas, muchas opuestas entre sí, lo que dio como resultado realidades e historias diferentes vertidas en un solo contexto. Así, en el libro se relatan las dificultades y luchas internas vividas por la gente para organizarse — aliarse a la guerrilla - o no: "organizarse significaba enmontañarse, medida considerada humillante y degradante, quizás sería buena para los indígenas pero no para los ladinos" (p. 71). Sin embargo, la masacre se convierte en un gran abismo entre un antes y un después. Para muchos significó corroborar lo que la guerrilla había dicho, el Ejército mataría a todos, organizados o no organizados: "entonces con la masacre empecé a arrepentirme de no haber creído" (p. 101). Una consigna utilizada por el Ejército para intentar legitimar la ofensiva contrainsurgente estaba detrás: "la guerrilla ganó muchos colaboradores indios. Por lo tanto, los indios son subversivos" (p. 42), matar a los indios era, bajo esa lógica genocida, luchar contra la subversión.
El texto se detiene en la masacre de Cuarto Pueblo, una de las más crueles de la época, no sólo por los 324 decesos, sino por la manera en que se ejecutó. Este acontecimiento cambió de manera radical la historia de la gente del Ixcán, no sólo de quienes fueron asesinados, sino de toda la población. Antes de la masacre había una "verdad" en disputa: ¿de qué era capaz el gobierno de Guatemala, de qué eran capaces el Ejército y la guerrilla? Se acusaba de patojos $^{11}$ a los que reproducían las historias ocurridas en otros lados: "ustedes no saben" (p. 231). Una verdad se desprendió de esa mañana terrible, la consigna de muerte al indio. El Ejército sí mataría a todos, por eso la gente huyó como y con lo que pudo, para salvar la vida. De manera paradójica, "el corte de la esperanza” impulsó a la gente a dejar sus parcelas y salir a la montaña, la organización se extendió sin consideración ideológica, "la masacre hizo crecer la organización en número” (p. 231).

Con una profunda mirada antropológica, Falla ofrece pistas para vislumbrar el papel preponderante de las relaciones de parentesco, religiosas y étnicas para tomar decisiones cruciales, sobre todo en los momentos previos a las masacres, y expone de manera particular cómo cierta ideología religiosa generaba gran resistencia a la organización. Así, abre un panorama para entender las motivaciones, miedos y reticencias de la gente, más allá de la dicotomía de estar con o contra el Ejército, discusión por demás explotada por ciertos sectores de la derecha, que en el mejor de los casos colocan al campesino indígena como un sujeto pasivo en un fuego cruzado (Stoll, 2003).

Otra de las grandes virtudes de este libro es que Falla menciona el nombre, y en algunos casos la procedencia, de cada víctima acaecida en ese periodo y

Forma coloquial y en algunos casos despectiva de llamar a los niños. 
región, 690 muertos y 18 desaparecidos, y con ello les devuelve un rostro y la dignidad; no los mira como cifras sino como los muertos de todos.

\section{La fuerza de la palabra}

Uno de los aspectos que más llamó mi atención es cómo se presentan los testimonios. Nos conducen de manera que uno puede sentir en ellos el miedo y la fuerza de la vida. Se exponen en forma de poesía y conservan el habla del indígena, que lleva un ritmo propio, el del dolor y la resistencia. Falla quiere comunicar algo más que los hechos en sí, "la voz de las personas no está relegada a un aparato testimonial" (p. xxxvi), busca poner en palabras lo inefable de las atrocidades cometidas. Esas historias resultaban increíbles, parecía inverosímil que lo ocurrido en Cuarto Pueblo fuera cierto o pudiera ocurrir en otros lugares; incluso hoy, algunos de los hijos y nietos de quienes vivieron los hechos encuentran difícil entender cómo aquello pudo suceder. Por ello este texto cobra gran relevancia, no sólo para entender lo que ocurrió en el Ixcán, sino en toda Guatemala.

Al leerlo, surgen la claridad y la comprensión de los hechos, percibimos el sentir propio del que escucha, y los hechos se convierten en algo que importa (Beverley, 2010: 16). La masacre y su relato se transforman en un símbolo que da sentido a lo inconmensurable y lo hacen semilla para la acción (p. 27).

Falla ofrece una mirada de la historia desde la experiencia de los subalternos, por demás constituida de esperanza y miedo, y no tiene reparo en mostrarlo, "la recurrencia del llanto, entonces, facilita la asimilación de la experiencia para pasar de ella hacia adelante" (p. 669). Las emociones vistas no constituyen un impedimento para la lucha y la memoria, sino que son sus motores, ondas que afectan a lo largo del tiempo y el espacio, su transmisión puede ser lenta debido a la represión, pero no dejan de propagarse.

\section{El sentir del resistir}

Por último, sin agotar las vetas del libro, Ricardo Falla proporciona una discusión rica y lúcida sobre los conceptos de población civil y resistencia. Ante las condiciones de emergencia, organizados y no organizados tuvieron que enfrentar la falta de alimento - el Ejército macheteaba las siembras y quemaba los almacenes - , la enfermedad - la gente se hinchaba debido a la desnutrición, la falta de sol y la humedad de la selva-y las persecuciones, que se hicieron cada vez más intensas. El Ejército forzaba a los campamentos a estar en movimiento, lo que desmoralizaba y facilitaba la presión para que la gente abandonara la selva y se rindiera o escapara a México (p. 402). Esto generó un nuevo tipo de organización, no sólo fundamentada en la lucha guerrillera, sino en mantener la vida.

Las condiciones existentes obligaron a la población civil a tomar partido, sin que eso la convirtiera en combatiente, pero tampoco se pensaba - ya no era posible - como imparcial o pasiva, era necesario emprender acciones. Esta condición se torna relevante cuando hablamos de genocidio o crímenes de lesa humanidad, lo que permite concebir a la población como un agente activo sin que pierda su condición de civil o admita que los grupos armados en conflicto se deslinden de culpas y responsabilidades.

Una de las acciones que la población civil llevó a cabo fue "aguantar", como se le solía decir en ese tiempo a la resistencia. Resistir implicó una autodeterminación por la vida. No se combatía con armas, pero sí se buscaba acabar con el enemigo. Esto supuso un nuevo recorrido de creatividad, una nueva forma de producción colectiva. Falla no idealiza el trabajo y la vida colectiva, al contrario, expone sus 
dificultades y contradicciones, presenta los acuerdos y disputas de la vida diaria en la voz de los sujetos. Sin embargo, "lo que mandaba era la necesidad y solidaridad" y al cabo del tiempo se demostró que era la mejor manera de sobrevivir (p. 597).
Resistir se presenta aquí como un hacer para vivir. El texto de Falla nos incita a ver los testimonios, no como una historia de lo que pasó, sino como gemido que nos conmina a actuar con y a favor de la justicia. D

\section{Bibliografía}

Asociación para el Avance de la Ciencias Sociales en Guatemala (Avancso), s. f., <http://avancso.org.gt/que-es-avancso>.

2014, "Comentario Ricardo Falla”, 29 de mayo. Disponible en línea: <https://www.youtube.com/watch?v=nOilRPeeOIO>.

Beverley, John, 2010, Testimonio: sobre la política de la verdad, Bonilla Artigas, México.

Brett, Roddy, 2007, Una guerra sin batallas: del odio, la violencia y el miedo en el Ixcán y el Ixil, 1972-1983, F\&G, Guatemala.

Comisión para el Esclarecimiento Histórico (CEH), 1999, Guatemala, memoria de/ silencio, Comisión para el Esclarecimiento Histórico/Oficina de Servicios para Proyectos de las Naciones Unidas, Guatemala.

Falla, Ricardo, 2005, Alicia: explorando la identidad de una joven maya, Asociación para el Avance de la Ciencias Sociales en Guatemala/ Universidad de San Carlos de Guatemala, Guatemala.

__ 2013, Al atardecer de la vida..., vol. 1: Del proceso de paz a la masacre de Alaska. Guatemala 1994-2012, Asociación para el Avance de la Ciencias Sociales en Guatemala/Universidad Rafael Landívar/Universidad San Carlos de Guatemala, Guatemala. Disponible en línea: <http://avancso.org.gt/ricardo-falla-sj/coleccion-al-atardecer-de-la-vida/>

__ , 2015, Al atardecer de la vida..., vol. 3: Ixcán, El campesino indígena se levanta. Guatemala 1966-1982, Asociación para el Avance de la Ciencias Sociales en Guatemala/Universidad Rafael Landivar/Universidad San Carlos de Guatemala, Guatemala.

__ 2017, "Investigando sobre el genocidio y la resistencia", conferencia presentada en la Universidad Iberoamericana, México.

- 2018, Al atardecer de la vida..., vol. 5: Ixcán. Pastoral de acompañamiento en área de guerra. Guatemala 1981-1987, Asociación para el Avance de la Ciencias Sociales en Guatemala/Universidad Rafael Landivar/Universidad San Carlos de Guatemala, Guatemala.

Garst, Rachel, 1993, Ixcán: colonización, desarrollo y condiciones de retorno, Consejo de Instituciones de Desarrollo, Guatemala.

Rappaport, Joanne y Mariela Eva Rodríguez, 2007, “Más allá de la escritura: la epistemología de la etnografía en colaboración”, en Revista Colombiana de Antropología, vol. 43, pp. 197-229.

Stoll, David, 2003, Entre dos fuegos en los pueb/os ixiles de Guatemala, edición digital del autor. Disponible en línea: <http://www.nodulo.org/ bib/stoll/edf.htm>. 